\title{
Knowledge Elicitation with Aboriginal Australian communities
}

\author{
Cat Kutay \\ Charles Darwin University, Darwin, Australia \\ cat.kutay@cdu.edu.au
}

\section{Abstract}

This paper provides techniques for engagement and data collection in researching with Aboriginal Australian cultures, acknowledging significant differences in forms of communication and usage of Information Systems to the mainstream Australian culture. An approach to trust in relationships is developed by interpreting cultural aspects arising from the diverse relationships to technology developed by Aboriginal users. This work uses the existing Honeycomb model for social media development as a base framework for collaborative web systems and online knowledge sharing in the Indigenous domain. We present a series of product development research projects based in universities in NSW Australia, in particular user experience studies, to explain the relationship between the researchers and users and the products that are created in terms of the model. Some concepts and processes fundamental to engagement with Aboriginal Australian communities in the supply of appropriate information sharing technology are discussed in this context. For if Aboriginal people are to engage in IS development, we are sharing the knowledge or the culture that is embedded in the technology which can have detrimental effects. Either we are asking them to enter the culture that created the technology, that is assimilate, or we use engagement in design to change that technology to suit the culture.

Keywords: Aboriginal Knowledge Systems, Protocols for Engagement, Appropriate Information Technology

\section{Introduction}

Research into Aboriginal requirements for Information Technologies is crucial for developing resources suitable for use by Aboriginal Australian communities as a means to share information. The requirements for such knowledge systems also considers the effect on community wellbeing of incorrect sharing, and by engaging for change we can reverse some of the detrimental effects of IT as it has been developed to date ( $\mathrm{Du}, 2017)$.

It is challenging to design appropriate technologies based on the requirements of a community culture that has been alienated from the culture where the original technology was developed. For Aboriginal communities in urban and remote areas, we work with different languages and world meanings. The historical dispossession of land, forced removal and the institutionalisation of Aboriginal people in Australia has reduced Aboriginal engagement, or willingness to engage in online systems (Radoll, 2015). This paper considers aspects of the development of consultation processes with the community over many years.

The significant features of research that arise in this context are around the relationship of users to each other and to any knowledge shared; and the methods used in knowledge sharing as a community narrative. It is this communal approach to knowledge that create particular differences. Within a community focus on knowledge sharing, we consider the values and 
relations around sharing information and how to promote engaging in a dialogical process with the community (Iversen et al., 2012).

While we consider how to negotiate knowledge sharing with Aboriginal communities, it is helpful to understand why there are different protocols for this process, to understand how these protocols translate into suitable actions and sustainable relationships across cultures (Ormond \& Slogget, 2008). For example, integrating IS with another culture involves twoway learning with the sentiment of "Ngapartji: We give, you give".

\section{Background}

Indigenist research is research by Indigenous Australians whose primary informants are Indigenous Australians and whose goals are to serve and inform the Indigenous struggle for equality. (Rigney 2001).

For Aboriginal communities there is an emphasis on knowledge negotiation prior to public sharing, in a form of oral peer review. A person will consider the significance of a new factor in the environment then stories about this will be discussed and shared for a while before they are considered part of the established knowledge of the region (Kutay, 2019). Supplying information systems to support cultural ways of knowing and knowledge sharing can conflict with such cultural and social values. To deliver technology for users to control and improve their own wellbeing we must deal with these conflicts, particularly to develop systems that support long term sustainability and economic benefits for communities, not just individual wellbeing.

There are issues for Indigenous cultures relating to the representation of traditional knowledge systems in new interfaces (Verran \& Christie, 2007). This requires an analysis of shared meaning amongst users from the community and the dominant culture. For example, considering unbalanced power, problems of trust and the development of relations with the users (Winschiers-Theophilus et al., 2012), but also new aspects around relationships and how these can be incorporated into online sharing. Also, there is a tendency in research with other cultures for researchers to compensate for differences they consider deficiencies that need to be countered rather than looking at opportunities to create new and novel networking systems, yet this latter aspect is an important aspiration in IS (Sidorova et al., 2008). The traditional techniques of socialisation of tacit knowledge can inform and enhance our present online systems for education and training (Kutay \& Aurum, 2007).

The difference in standpoint from an Aboriginal and non-Aboriginal perspective will vary according to the domain of investigation. We look at the variation of ideas in the knowledge sharing and collaboration processes and how to incorporate these ideas in ongoing research. These systems focused on knowledge sharing in the form of stories as audio or videos, as well as images, text and documents promoting events. We use web sites and mobile apps, but also require data management to support protocols and included immersive game environments. This work is the result of years of design and development work by Aboriginal and nonAboriginal researchers in urban and rural NSW Aboriginal communities. 


\section{Literature Review}

Strong cultural identity and community and family connections, which can be enhanced through social media, are linked to improved educational and health outcomes (Rice et al., 2016)

Social network growth online can mirror relationships that are strong in Aboriginal families and communities. However, there are clearly cultural or institutional issues that affect the take up of any digital resources. The development of technology should always consider the target audience and their world views, particularly when aiming to support psychological wellbeing, since this itself is a construct that has different representations in the epistemology of different cultures (Goldfinch et al., 2016).

In terms of wellbeing there are the two-fold benefits for Information Systems development, of acknowledging and crediting Aboriginal knowledge; and providing the platforms for sharing stories to create greater identity and value with the community.

\subsection{Indigenous relations with Information Systems}

It is through developing a relationship to knowledge and valuing the means by which we gain this knowledge, that Indigenous people gain insight and claim a right to express this knowledge (Wilson, 2008). From previous research into Aboriginal use of the Internet (Radoll, 2010; Dyson \& Underwood, 2006; Kutay, 2010; Akama et al., 2016) it has been found that it is important to consider Aboriginal Australians' relationship to online media through various aspects from how Indigenous people relate to knowledge. The areas extracted from previous research can be summarised as:

- Control and Identity: The general lack of experience in IT reduces the possibilities envisaged by the community in designing with this medium. This creates a lack of understanding of what is possible with technology to express community ideals and what are the risks. However, an online presence is considered part of Aboriginal expression of identity. (Rice et al., 2016)

- Communication: Aboriginal English or Aboriginal oral languages are usually the peoples' first language, so audio or visual formats can be more suitable than text. Also, a language carries a mode of thought, and existing cultural ontologies that are used online create boundaries in the interface, the choice of content matter, and how to link material. (Eades, 2013)

- Collaboration and ownership: The shared governance used in Aboriginal communities is not easily replicated in database systems. A suitable IS system requires control to be divulged more to the users. Many of the issues relate to ownership, where the community can feel they understand and control the system enough to feel trust and empowerment in using the system. (Radoll, 2010)

- Access and Transferability: Build systems for the majority of users who are limited to mobile internet access and incorporate the needs of disabled users who are well integrated into the community. To improve access, we also look at how resources developed for one group may not be relevant for other groups in terms of interface design, preferred functionality or accessible data, however patterns in design can be extracted (Dyson \& Underwood, 2006). 
- Immersive: Increased value of immersive online environments such as VR games to provide a knowledge interface, given their relation to the holistic approach of Aboriginal ceremony used in teaching. Also, this helps counter the fact that online communication removes knowledge from its physical environment which is a fundamental part of knowledge transmission in Aboriginal society (Kutay, 2010).

- Relationship to knowledge: Provide different access to knowledge based on these relationships; and ensure the knowledge derived through the development process is part of the final product; and being part of this process allows Aboriginal users to feel ownership of the product. Also acknowledging the difference between different communities' relationships requires flexibility in the knowledge management between versions of a system (Akama et al., 2016)

- Trust relationships: The issues of trust of both the online systems and of relations with non-Aboriginal viewers when sharing knowledge is well studied. Aboriginal protocols are based around contributors' relationships to each other and provide a way to trust information that is shared, and these need to be emulated in some form online. The need for trust includes: establishing relationships with those sharing knowledge through online tools; ensuring that knowledge will not be misused or misinterpreted out of context by those without relationship to the knowledge; maintaining protocols for knowledge sharing through the online interface; and supporting normal community methods of verifying oral knowledge through collaboration (Povinelli, 1993).

- Novel approaches: Users with novel ideas for what could be done creates innovative development ideas beyond the scope of these projects. Locating the situation through different cultural framing is part of finding the solution and forms a continuous iterative development in co-creation (Soro et al., 2016).

In the gathering of community requirements for a new system, the IS designers often act as both facilitators and change agents, which is contentious (Winschiers-Theophilus et al., 2012). However, the process of agile development does facilitate the user to understand various prototypes which helps them assess the options available and realise the flexibility of ICT's. Digital literacy is often not an issue in community (Prayaga et al., 2017) so we consider other factors that have come out of our projects.

Many of the factors presented in this study contribute to both community engagement, important for the cross-cultural technology development; and ensure Aboriginal people see benefit from projects in community terms. What is required is an understanding of the significance of any information given (e.g., a painting to be used on the web or mobile app) as spiritual and linked to the wellbeing of the community and country, not just the artist or author.

\subsection{Honeycomb Model}

The Honeycomb model (Kietzmann et al., 2011) has provided a tool to analyse key features in new social media systems for their effectiveness. The concepts in this model were found to map well to all the issues above which have been located in research into Aboriginal relationships with internet sharing. Social media is an environment that considers people in relationships, an aspect that is significant in Aboriginal world views. 
This process is best understood in terms of socialisation of knowledge (Nonaka \& Takeuchi, 1995) often initially through teams of developers and community members, for example in student run projects (c.f. Ayala et al., 2015). Also, the aim of these projects is for more broader socialisation of this knowledge, either within community or externally, through internet media. Considering the Honeycomb framework is useful for analysing socialisation on the web in specific platforms, we looked at how this applies in past experiences and the aspects important for the future development of systems for Aboriginal community sharing.

The model has been used to understand significant factors in developing social media and gaining benefits from this type of online community for businesses and other users (Silva et al., 2020). While this paper is about more conventional websites such as blogs and Content Management Systems (CMS) sites, it is about how we extend these to provide a social environment for collective knowledge to be collected and presented.

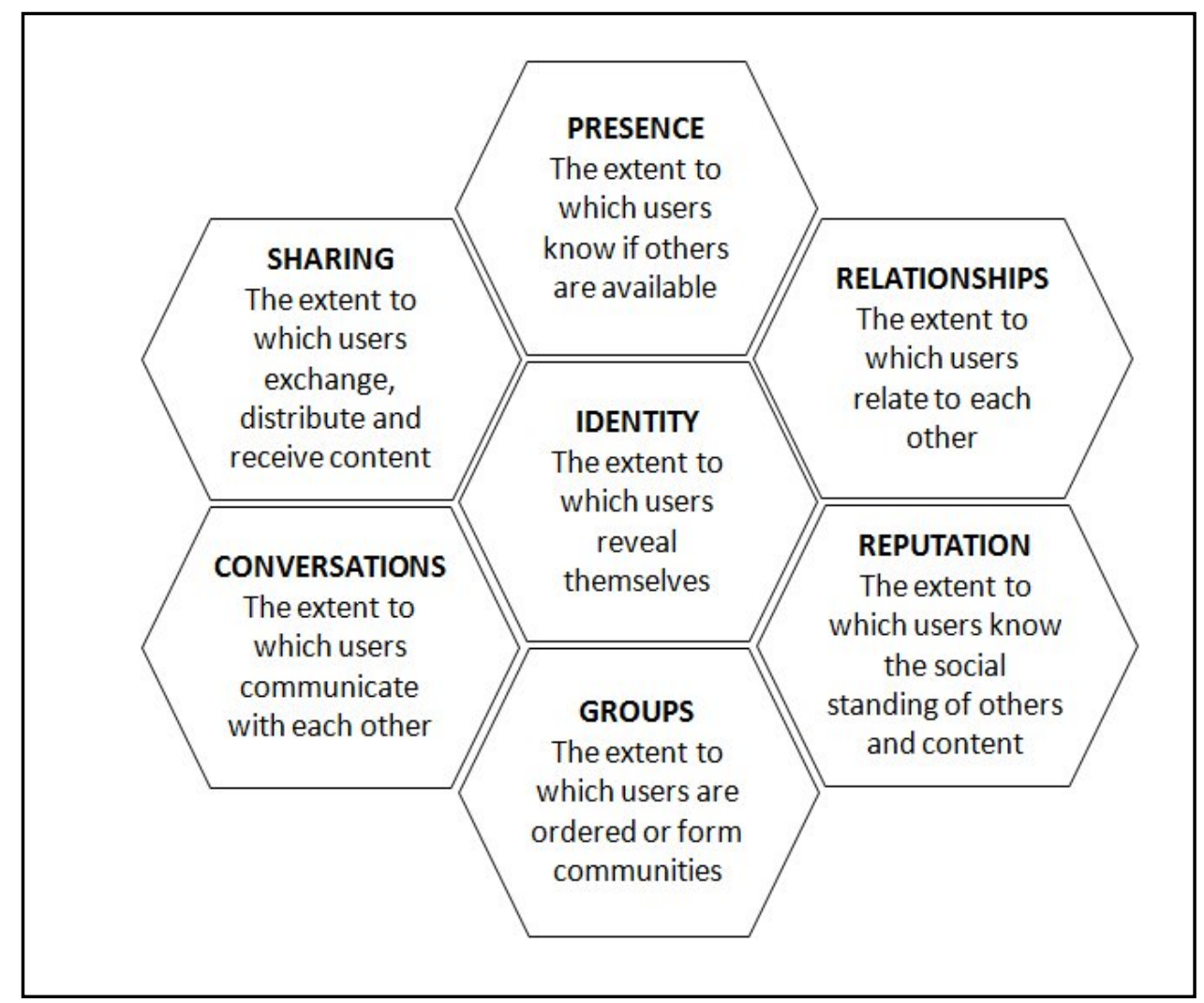

Figure 1. The honeycomb framework of social media (Kietzmann et al., 2011 p. 243)

\subsection{Requirements gathering in the Indigenous space}

Ethnographic research tools and narrative methods have been used in software requirements gathering for many years and have aligned well with the storytelling approach to knowledge sharing used by Aboriginal groups (Lukosch et al., 2009; George et al., 2011). New aspects also arise to be considered, such as humour, dance and music to be incorporated in systems, but also new interpretations on imagery (excluding "the other") and relationship between the users. Novel requirements such as limiting access to knowledge according to a user's status and their prior knowledge (Radoll, 2015) are important in Aboriginal society and should be maintained online to develop community trust. 
Existing models of social media systems used in Information Systems research provide a unique opportunity to examine Aboriginal use of these systems as a form of sharing and developing public relationships with Aboriginal knowledge. The Honeycomb model (Kietzmann et al., 2011) is used to evaluate group sharing sites developed within community groups (c.f. Senadheera et al., 2017) as a form of limited social media.

\section{Projects studied}

The series of projects in this study as listed in Table 1 and discussed below exemplifies the gradual process in creating an Aboriginal knowledge sharing system. Time is needed for Aboriginal people to develop a relationship to the technology and system of knowledge access that has been created on the internet and develop ways to manage knowledge sharing in line with existing values and beliefs.

The projects developed from collecting material for individuals to use; to providing networks between groups; to interfaces for sharing material to be used as a community narrative in teaching; and using the community material to develop games. It has been interesting that other forms of networking that have developed have been adaptations of existing technology like Facebook through restricted groups, and creation of bespoke systems like Keeping Culture (n.d.), Mukurtu (n.d.) and Limba (n.d.) have developed into templates for other communities to use and adapt.

\begin{tabular}{|l|l|l|}
\hline Type of resource & Content Type & Aim \\
\hline Online repositories & $\begin{array}{l}\text { Stories sorted around themes such as } \\
\text { stolen generations }\end{array}$ & $\begin{array}{l}\text { Knowledge collection: Public education } \\
\text { through a series of oral histories around a } \\
\text { theme }\end{array}$ \\
\hline $\begin{array}{l}\text { Search engine of } \\
\text { reports for DAA }\end{array}$ & $\begin{array}{l}\text { Compare and combine reports on the well- } \\
\text { being outcomes of projects across many } \\
\text { different communities (Kutay, 2010) }\end{array}$ & $\begin{array}{l}\text { Knowledge collection: Support workers } \\
\text { to collect material around a theme from } \\
\text { community reports }\end{array}$ \\
\hline $\begin{array}{l}\text { Sydney Koori } \\
\text { Interagency Network }\end{array}$ & $\begin{array}{l}\text { Mashups in php, javascript and python as } \\
\text { a template for a multi-site system (Kutay, } \\
\text { 2010) }\end{array}$ & $\begin{array}{l}\text { Collaborative Information service: for } \\
\text { information sharing across NGO's and } \\
\text { Depts with Aboriginal workers }\end{array}$ \\
\hline $\begin{array}{l}\text { Indigenous remote } \\
\text { media outlets to } \\
\text { collect and distribute } \\
\text { material }\end{array}$ & $\begin{array}{l}\text { Community upload and video streaming } \\
\text { through Indigenous Remote } \\
\text { Communications Association (IRCA) }\end{array}$ & $\begin{array}{l}\text { Collaborative Information service: to } \\
\text { share media to re-broadcast through } \\
\text { satellite to all remote communities. }\end{array}$ \\
\hline $\begin{array}{l}\text { Sharing language } \\
\text { resources to combine } \\
\text { into worksheet for } \\
\text { teaching }\end{array}$ & $\begin{array}{l}\text { Combining online language resources for } \\
\text { teaching. Resources analysed from } \\
\text { repository to show relevant material on } \\
\text { worksheet (Kutay et al, 2012), }\end{array}$ & $\begin{array}{l}\text { Collaborative knowledge sharing: for } \\
\text { teachers and students to learn language } \\
\text { through oral and text repetition across } \\
\text { different interfaces. }\end{array}$ \\
\hline $\begin{array}{l}\text { Academic- } \\
\text { community sharing } \\
\text { stories }\end{array}$ & $\begin{array}{l}\text { Tools to allow community to link stories } \\
\text { online into teaching resources (Soro et al. } \\
\text { 2016), ALTC (Kutay et al., 2012) }\end{array}$ & $\begin{array}{l}\text { Collaborative knowledge sharing: } \\
\text { Community stories linked under } \\
\text { teaching topics for university } \\
\text { engagement in cultural knowledge }\end{array}$ \\
\hline $\begin{array}{l}\text { Gamification of } \\
\text { knowledge }\end{array}$ & $\begin{array}{l}\text { Linking online material through } \\
\text { Application Programming Interface (API) } \\
\text { to games and mobile apps }\end{array}$ & $\begin{array}{l}\text { Tacit teaching; Interfaces to share tacit } \\
\text { components of knowledge and reinforce } \\
\text { narratives. }\end{array}$ \\
\hline
\end{tabular}

Table 1. The studied projects

This process of networking around information systems began through gatherings such as conferences and workshops run by Indigenous groups, through projects shared at public 
award ceremonies, and through those seeking for a solution to a problem by approaching other communities as to how they are dealing with such issues. Aboriginal experience of distrust and misunderstanding merely highlight the need for this initial face-to-face component of knowledge sharing.

Meeting in person is the only way we can truly trust and understand the person we are talking to, as was found in the initial project with the Department of Aboriginal Affairs in NSW (DAA), when trying to share project successes, a detailed account of how the project was implemented in a specific context is required to verify if it will apply to a new context. The ongoing issues with online security merely exemplify this conundrum for online Aboriginal businesses.

\section{Knowledge collection}

There are significant aspects to consider in order for Information Systems to support Aboriginal sharing of knowledge. We need to understand the perspective of the users, and how these develop over time with growing experience and engagement.

...[T]he fact that our vision of the world is a vision from somewhere, that it is inextricably based in an embodied and therefore partial perspective, .... makes us personally responsible for it. The only possible route to objectivity on this view is through collective knowledge of the specific locations of our respective visions. (Suchman, 2002, p. 96)

\subsection{Storysharing from community}

The first projects were to stream stories on the Stolen Generation (outside YouTube for security reasons) and the second to develop an interface for a web portal of community or Government information on Aboriginal projects at the NSW Department of Aboriginal Affairs (DAA). This site was designed as an annotation system. These were both designed for communities or community members to share experiences with other communities or individuals who may have similar issues (Kutay, 2012) as well as educating the public or government workers on community concerns.

The work used previous activities and experiences of Aboriginal communities in story sharing and collating knowledge under themes for ceremonies (Verran, 2007), as done prior to the online experience. The requirements focused on the users' affective motive or intent, their perception or awareness, their desires and beliefs (Fishbein \& Azjen, 1975), as well as the familiar forms of knowledge sharing, and considered how to transfer this experience to online use (Verran et al., 2007; Kutay, 2011).

\subsection{Collaborative Information sharing for Aboriginal workers}

The second two projects were to: develop an information sharing resource for government and community workers in a joint Sydney Koori Interagency Network (SKIN); and for remote radio and TV to share broadcast material (IRCA).

For the Joint SKIN groups, prior to the project this communication was done through face-toface meetings and manual distribution of emails, but this was causing duplication of information and was providing a bottleneck that was managed by a few Aboriginal workers in government who were under pressure to stop spending their time on this work. However, they saw this as a vital part of their role in engaging and informing the community. 
For remote communication groups there were many independent Remote Indigenous Broadcasting Services (RIBS) stations set up in different languages, however they could often share media. While sharing the broadcast expense by combining into one network was advantageous, the sharing of stories around common themes or stories was also considered a major benefit (Sawhney \& Ratnadeep, 2008).

In both cases the final sites were well received but over time the growing experience of the network members necessitated upgrades to more modern looking sites, and SKIN developed sites as separate entities for each regional group. The media communication site now has extended to a live video streaming service for radio and TV shows but retained the collaboration.

\subsection{Collaborative Knowledge Sharing}

For the community sharing projects, we were working with community creating knowledge that was recorded specifically for the site. A long-term project run with community language nests and language centres around NSW, has been to supply online systems to provide an interface to language resources in any media. Such resources are: recordings from the Australian Institute of Aboriginal and Torres Strait Islander Studies (AIATSIS, n.d.); transcriptions of these; images from Aboriginal people; grammar and examples from linguistic research; and new recording from existing speakers usually as videos in situ on their own land (on country).

In language sharing work we used web services across many communities and allowed users to select not just the language groups they relate to, but also the family or clan as each subgroup had different approaches to images to use and pronunciation of language. The site included systems to analyse the various material available in the repository and select for a worksheet topic, then display this on the interface. Also, this has been linked to a mobile app to reinforce the oral wordlists with example sentences.

A similar project sharing stories was run with a two-year Federal Government Office of Teaching and Learning grant (ALTC). Aboriginal academics were involved in a story gathering process to provide material to augment an online site for training students in the Indigenous perspective on their discipline, including education, law and social policy (Kutay et al., 2012).

The project was to develop interactive learning scenarios based on the experiences of community members in an educational, legal or social development setting. Stories were given by the community and provided personal experiences, and were combined to provide the introduction to ideas to discuss and develop in the scenarios.

While the scenario scripts were written based on the ideas provided by community members, many were not generalisable in the form of community narratives. Also, those developed for lecturers in one state did not represent the experience of Aboriginal instructors in other states. The various histories of colonisation and the experiences in reserves or missions creates different approaches to education.

\subsection{Gamification of Collated Knowledge}

The recent projects have built on the material collected online and developed tools to extend these into interactive mobile apps and games as a learning support. This was mostly focused on the language teaching sites, but we are extending this to more procedural knowledge. 
Gaming strategies are also useful platforms to introduce various cultural priorities such as requiring the player to collaborate to finish (Lightning Runners, 2018) or to expand on earlier stories in the game in the context of the developing environmental experience of the player.

The first game template has been developed using the API interface to the language learning web systems. This has been used for simple mobile app for word reinforcement through oral examples. Now it is being embedded in a game where the language can be used in a context. Aboriginal animators are developing the animations in the game to provide authenticity of gestures and interactions of characters. The game is based on the Dharug language of Sydney to embed in a $2.5 \mathrm{D}$ representation of that environment using the images of Joseph Lycett, an early convict artist who provides use with authentic representations of Sydney during early invasion

\section{Community of practice}

We now look at the findings in each project relating to the aspects extracted from previous research as described in section 2, relating previous research to the Honeycomb model and draw out the relevant experiences from the projects described. This relates back to the growing interest in Aboriginal culture in Australia and encourages the utilisation of the Aboriginal community as innovative partners in IT development, both for Aboriginal wellbeing, but also for broader engagement in changing how we relate to technology.

The Aboriginal community has for a long time maintained independent networks to mainstream Australia, so we look at how this practice has been developing online and how community has taken control of this social and voluntary media to create new networks of practice (Wasko et al., 2004). Using the honeycomb model of social media analysis, we consider how this can be expanded around Aboriginal use of internet media, as a tools for requirements gathering.

\subsection{Identity and control}

The lack of community control revolves around the lack of 'elders' or knowledge holders in this space which makes it hard for people to move forward with certainty. This creates a lack of experimenting that developed understanding of what is possible with technology and what are the risks. This falls in the area of identity in the Honeycomb model as the community does not identify with any expertise in the domain of providing requirements for a system.

The way that community groups will adapt or adopt technology is important, and how to engage such groups early in control of the process to increase engagement. The concept of community or personal control of technical services is quite foreign and hence there has often been limited engagement in co-design (Carroll \& Rosson, 2007).

The starting point for each co-design was setting up the project from a community request for technology and engaging the community in this process. This involves considering communities as the project managers and taking a broader perspective of the values, norms, beliefs and assumptions which give legitimacy to engagement with Information Systems (Mignerat \& Rivard, 2009; Kutay, 2011).

Since in institutions we know that "coercive, mimetic and normative pressures are control mechanisms exerted" to constrain adaption of technology (Mignerat \& Rivard, 2009) we look at the main areas of control to be divulged to community to enhance engagement. 


\section{- Platform}

The complexity of available platform options, and the risk that some options will not be viable for long is a difficult area for community to engage in the decision process. In practice the platform has been chosen from what is available in the space (e.g., email systems, CMS) and used in a mashup prototype to allow community to familiarise with the system. However, with the rapidly changing IT environment, sometimes the system chosen does not survive long for re-use, particularly in the mobile app domain.

- Interface

Community can select and develop the interface design. Artistic members appreciate the opportunity to produce relevant work if time and funds are available. Also, this engages an understanding of the underlying ontology of the system as part of the requirements, as the values and perspective of the client are very different (Tacchi \& Watkins, 2007). When extending into gaming, animation skills from the community are harnessed in a new and exciting ways.

- Data access

As well as communities wishing to control access to data by specifying a user's affiliation to communities and family or clans, we encountered designs for new forms of access such as the use of paywalls for a collation of community artefacts.

\subsection{Conversations}

The language and grammar or ontology of the site requires a redesign of our approach to knowledge networking. For a project to succeed with community we need two way sharing to develop understand of knowledge structure across cultures. We used online engagement familiar to users where Aboriginal people can practise more familiar and informal forms of information sharing that are similar to prior activities (Smith et al., 2000).

Integrating social networks processes with serious information sharing systems can introduce users with resources they both consider worthwhile, and trust to be productive by referral from the community. However, we need to understand the relationships being developed. There are two main factors that stand out in an analysis of the community relationships: existing divisions between families or clans; and involvement of all ages in knowledge projects at different levels (Kutay, 2007).

There is also the unique narrative form of knowledge sharing across groups, through the dreaming stories that are told from childhood. These grow with the listener to become the framework of a holistic approach to knowledge (Sveiby \& Skuthorpe, 2006) for future understanding.

\subsection{Groups}

For the management of a social network, the existence of distinct groups within the Aboriginal community needs to be acknowledged and all contributions to decision about any systems need to be considered. The SKIN website was always a conflictive process of requirements gathering as different centres had different needs and tended to fear that others needs would affect the way their own site was structured. While the agencies wanted to run with their own priorities, they also wanted a unified system as there was a lot of commonalities across the teams in Sydney. 
The other aspect was access between groups. The design of databases around a central administrator caused much concern for Aboriginal users and the use of Aboriginal knowledge protocols should allow systems to restrict who can access different artefacts (Radoll, 2009). We are supplying front end systems such as Mukurtu (n.d.), which allow the community to set up protocols of access. This however retains the original power of the single administrator, rather than a role-based system, which creates trust issues with users.

As in the ownership over knowledge, Aboriginal people expect a high level of ownership of and engagement with technology. This process requires two features in a technology: the technology fits the culture, i.e., it is appropriate and hence useable; and the community is engaged in the design or maintenance of the technology in some way. Then we are embedding the new cultural knowledge in that IT, the knowledge becomes part of the artefact, and so Aboriginal people can consider they own the product.

\subsection{Sharing}

Access is an issue about the ability to connect and share material, a two-way process. When developing for mobile use there is a desire to provide cross-platform systems due to the small community of users being catered for. However, to store material from users a native system or good internet access at all times is required, so browser-based technologies on mobile were not feasible at the start of this work.

Now with Progressive Web Apps (PWA) and background syncing, the sharing of data from mobiles, in fact the authoring of online material from any device, is much improved. The value being given to the user is increasing. Apps such as Questagame which is a citizen science project, have been taken up by Indigenous groups looking to promote sustainability through education in environment across all ages, and this desire to share online has increased during the coronavirus pandemic.

Due to the small market for the applications developed with Aboriginal communities, template systems are being promoted to allow communities to adapt the interface for a specific use while retaining functionality and storage that is managed and costed in common (Pradhan et al., 2018). These designs require an analysis of cases across many communities (and Indigenous enterprises) to consider the common features of the model to design the template and ensure the functionality covers all system types.

This has been difficult in the conflicting environment of government funding for the development of Aboriginal applications, but some departments are starting to realise that many grants are going to similar projects and some cohesion could improve the production of resources (e.g., language mobile apps).

\subsection{Presence}

For Aboriginal users in the system the issue of presence is not so much who is present, as people live within a strong community outside social media, it is more around the ability to immerse in the environment of the knowledge being shared, so that it is true to the time and place that is being recorded.

Existing technology for developing games and augmented reality systems provides opportunity to develop more authentic environments for knowledge sharing that will create trust amongst more traditional Indigenous groups, such as the Kakadu elders who share their 
stories with the young in a new Augmented reality project (Indigital, n.d.) where the story is present with the background of an existing artwork.

Aboriginal knowledge sharing practices are based in the country where the knowledge is from and much of this relationship can be maintained through existing virtual and augmented reality technology (Kutay, 2018). Also, the use of storytelling techniques to link material around common themes relates to Aboriginal knowledge sharing practises. In this way a more holistic understanding of knowledge can be taught through community collections of stories.

\subsection{Reputation}

The issue that arises over trust and security is over who you are sharing the information with. it is important to know who is present and what can be shared. The reputation of a person sharing knowledge is based on their relationship to the knowledge being shared, either through Aboriginal law or through personal connection (Povinelli, 1993) on whom they can share this knowledge relies on similar aspects of relationship (Kutay, 2021).

Given the recognised conflict in security between information sharing and information protection we found it important to involve community in being able to set up the security and access systems required. The link between learning a system and uptake of IS exist, but particularly security issues have an effect on user engagement (Wasko et al., 2004). Online systems like Limba (n.d.) provide a system of communities and protocols that can be selfselected, or community imposed, providing some autonomy in this learning process.

\subsection{Relationships}

Developing relationships online is not just between people but with the knowledge that is shared. This may be around land where the material is from, the status of the provider, etc. But there is also the relationship to the technology itself, in that community will not be engaged if there is not a cultural expression within the requirements to place the material in a suitable context.

Time is required to gather user stories and suitable imagery to provide a visual and intuitive interface, in particular there is a need for suitable icons that represent Aboriginal priorities. Similar work for the Penan language project has shown that such visual cues will vary across generations, as well as from other factors (Zaman \& Winschiers-Theophilus, 2015). The interface will be the environment in which this knowledge is now presented.

\subsection{Beyond}

The aspect that the Honeycomb model does not go into is the opportunities for the users to innovate and advance the social media network over time.

Since these projects were carried out there has been further developments, such as growing Aboriginal use of social media (e.g., the shared twitter handle IndigenousX) and the rapid uptake of mobile technology shows a skill in innovation and technology (such as Indigital, n.d.). It is the role of those who study Information Systems to observe and credit the new approaches being developed. 


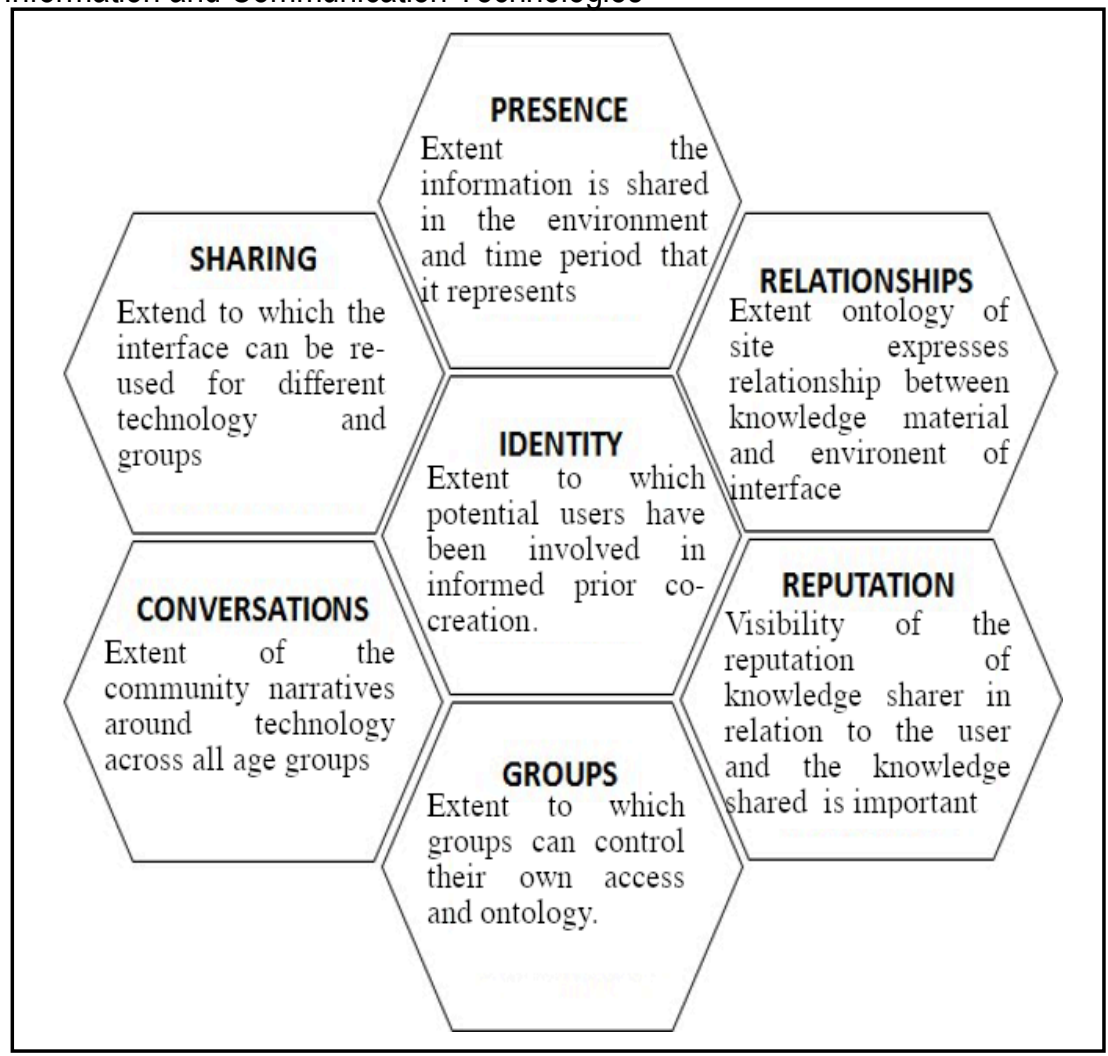

Figure 2. Honeycomb framework for embedding Aboriginal Australian community in Design

\section{Acceptance Model for Knowledge Management}

When sharing Aboriginal knowledge, we defer to the country or territory of the speakers. Knowledge about country is embodied in that land. Aboriginal people in reviving language see this as reclaiming it from country, that the knowledge still resides there and only being relearnt. This is partly as much of the knowledge is about country but also as the knowledge sharing system, the Dreamtime stories, are very much based in country, using landscape features to 'trigger' an aspect of the story to embellish to deepen the knowledge of what that feature represents e.g. 'this is where the flying fox ate the lilly pilly' will link to further material about the plants the flying fox eats, where they grow and the seasons of prolific food, and often the stories will locate in place and season by the stars that are overhead at the end (Kutay, 2019).

These projects are a way of highlighting the areas ahead in this process. The areas of system requirements can expand to consider consensus for social good; technology acceptance models based on cultural beliefs, attitudes, intentions, and behaviour for cross-cultural development; the study of social media use amongst community members will help understand how social relationship networks form in general; and knowledge management strategies developed in community will provide ideas for novel interfaces for eLearning and online knowledge sharing enterprises.

We present here some further issues for consideration around a knowledge sharing model for Aboriginal Australian Information Systems development projects. These provide examples of the Honeycomb model in practice. 


\subsection{Sharing in Different languages}

The process of sharing technology involves training in the use and creation of this technology, so the language and the knowledge travel with the artefact as it is traded (Pascoe, 2014). Aboriginal people talk about a story or piece of knowledge being 'in' an artefact, that a piece of the person creating a tool or story remains in that artefact. Hence for Aboriginal people to engage with the technology within their community life and language sharing is important but hindered by cost and suitable infrastructure in homes to access the internet (Gaidon, 2007).

In Australia designers work in a language of a very foreign culture, that derived from England. While cultural protocols provide cohesion in protocols across different peoples through sharing technology and knowledge, Aboriginal people are still often divided through language and cultural difference. It must be acknowledged that as researchers we are entering that conflicted domain (Nakata, 2010) when we seek to develop mutual understanding. We need to understand our own systems before we can open these to change.

\subsection{Working across Communities}

Planning a project to be carried out around a common theme requires that time is spent so that all options are discussed openly, and the effect of each option be understood by all parties. This enables Aboriginal people to take agency in the process and to ensure that the consequences are understood by all, through consensus decision making.

While the aim is to share resource between many groups at once with similar needs, this is not always feasible due to the different aspirations of different communities. At other times the role of developer is to find the common features to provide an integrated interface for many groups combining their resources.

Time must also be given to gather the stories and imagery that are relevant to a project, to provide a visual and intuitive interface. In particular there is a need for suitable icons that represent Aboriginal priorities, as shown in the recent development of Aboriginal emojis. Similar work for the Penan language project has shown that such visual cues will vary across generations, as well as from other factors (Zaman \& Winschiers-Theophilus, 2015).

\subsection{Conversations for Sharing Knowledge through Narrative}

The use of community narratives provides opportunities for different elders or experts to insert new information at relevant points in the story, a form of narrative wiki; and a way to allow community to contribute to growing the story over time as a collective narrative (Kutay, 2019). This provides opportunity for different voices to enter the narrative from their expertise, to make the internet a more collaborative presentation of information.

However, information that is specific to Aboriginal people, the knowledge of the land in Australia, is a knowledge that is very time and place bound. It cannot be shared in perpetuity without moderation of what is relevant at the time of viewing; what part of the cycle we are in (la niña, el niño); prior understanding of the viewer, etc.

\subsection{Identity is Holistic Knowledge}

Approaching knowledge that is holistic, from a European framework that seeks to break down knowledge into component parts, means that we need to start with the whole picture in order to find common ground to talk. This conflict between knowledge systems creates issues for 
Aboriginal people working with projects that are not holistic, as was described through the work to convey knowledge of firestick burning to western scientists:

The very features which provide its main significance in an Aboriginal knowledge tradition (where this particular plant happens to be for these particular people at this particular point in their lives, who is telling the story, why they are telling it here and now, and how the story fits into the wider networks of kinship, art, music, ceremonials and philosophy) are lost in the process of abstraction which records how any plant of this particular species in any location might be of use to any person at any time (Christie, 2005)

\subsection{Respect by Following Protocols}

There are existing protocols for research in Aboriginal knowledge (AIATSIS Ethics, 2020) which also cover some similar points, such as the need to understand the stories of each group of people. These define the access rights of the project and the way that community will retain control over the work.

In relating to the community, the researcher can learn how people are expected to behave in a culture. Simple rules such as "do not look Aboriginal people in the eye, this is rude" can be irrelevant or counter-productive for those community people who have grown up in the dominant culture, or who do not have that reservation. While there are common features across Aboriginal culture, much of the knowledge of the protocols will result from engagement with the community and making many mistakes (Kutay, 2021).

\subsection{Reputation Involves Understanding Context}

The two-way partnership with a community comes from understanding the people and their needs sufficiently to explain to them the technology and engage them in the design. This increases the reputation of any external researcher as they show they understand the people. This process also enables the researchers to understand the limits of the designs and concepts to the new environment.

It is important when returning to a project with a new prototype that the community be informed of what changes have been made and the reason. These must be shown as derived from the community engagement with the technology, since that may have been misinterpreted. To hand over control we need also to hand over understanding of what is being controlled.

\subsection{Creating Novel Uses}

Less often projects deal with the benefits that Aboriginal people bring to then, which is due to the reputation of Aboriginal people as knowledge holders. When developing applications for Aboriginal users are we providing something for the benefit and wellbeing of the user, or is the technology another extension of mainstream control and influence? Are we providing people with an opportunity to both take advantage of new technology, and to use this to improve wellbeing?

Are we open to accept a new use for technology, such as the requirements of limiting access to knowledge according to a user's status; prior knowledge; and deceased status (Radoll, 2015)? Information Systems research provides a unique opportunity to use existing models such as the Honeycomb model. Such models can be expanded to analyse the adaption and 
implementation of resources in Aboriginal networks and enterprises (First Nations Media, n.d) where community identity exists across vast areas of Australia.

\subsection{Relationship prior Knowledge}

From an Aboriginal holistic viewpoint, the scientific method often used of isolating a variable or two to explain a life phenomenon is not considered a valid approach to knowledge. In fact, the entire environment will both be part of the variables and be the location of the knowledge (Bidwell et al., 2008; Verran \& Christie, 2007).

This relationship to knowledge is different to that held by Non-Aboriginal researchers who can only hope to understand a translation of such a view of the world, and how people act in this world, through Aboriginal people who have the time and inclination to cross the 'cultural frontier' (Nakata, 2010). An important aspect is the significance attached to relationships rather than individual roles (Kutay, 2014).

Hence the collection of data on the community use of the technology (cf. Soro et al., 2016) is an important guide to re-develop the prototype over time, and this data can be interpreted by the community itself. It does not need to be an assessment imposed externally.

\subsection{Understanding Time}

In developing relationships to knowledge, the Aboriginal viewpoint incorporates a continuum that blends into a spiritual view of the world. We cannot ignore or belittle this perspective simply if it does not fit western knowledge system. Aboriginal spirituality is expressed as the way of knowing things from a pattern, matching over events, e.g., the sight of a willie wagtail is the sign of news. This means that the environment is acknowledging the individual and providing signs, forecasts, and warnings, that there is significance in the world.

Timelessness as used in the dreaming stories is part of the method for verifying knowledge on a large-scale level, which is not experimental or world changing, but world observing and world understanding. It is a knowledge system that links more closely to the specific environmental location or system on which we depend for living, than does western scientific process, and it holds a much greater value for human wellbeing as part of a community than an economic approach to land management.

This could be supported by a system that analyses the user's actions, e.g., Facebook relationships, and provides feedback on how strongly they are relating to those around them and use more natural (e.g., animal) images to portray concepts to incorporate a broader understanding of what is significant in our world.

\section{Conclusion}

Aboriginal Australian people's world view is strongly influenced by the environment in which the culture developed. We believe the technology and knowledge transfer needed to maintain this culture can be better supported in Information Systems through activities that allow communities to participate in the design and management of systems. We provide a model that has been developed from experience mainly in urban and rural NSW with Aboriginal community projects. However, we believe these issues will arise in other areas, such as some work done in the Northern Territory with remote radio support online. 
This may start with the interface design, the ontology of the knowledge system; and then extend to developing the components. So eventually communities can be in control of the systems and provide ongoing innovations in this area. Frameworks that highlight the significant features of a system, the different aspects to be considered in design, are important in this work.

\section{Acknowledgement}

This work was supported by various Aboriginal organisations who sought to engage in developing and using Information Systems for sharing ideas with the broader community. Thanks for their patience to Robert Leslie, Coordinator Joint Sydney Koori Interagency Network, Gary Williams, CEO Muurrbay Aboriginal Culture and Language Cooperative, Lynette Riley, Sydney University Koori Centre, Anthony Siever and Cathy Eatock, NSW Dept, Aboriginal Affairs, Dixie Link-Gordan, Mudgin-gal Aboriginal Women's Cooperative, Daniel Featherstone and Rita Cattoni IRCA. I would also like to acknowledge Olivera Marjanovica, Professor of Information Systems at the University of Technology of Sydney who spent some time advising me on my research focus and directing me how to present my work.

\section{References}

AIATSIS (n.d.). https://iats.ent.sirsidynix.net.au/client/en_AU/external. Retrieved August 15, 2021

AIATSIS Ethics (2020). Australian Institute of Aboriginal and Torres Strait Islander Studies (AIATAIS) Code of Ethics for Aboriginal and Torres Strait Islander Research. https://aiatsis.gov.au/sites/default/files/2020-10/aiatsis-code-ethics.pdf. Retrieved August 15, 2021.

Akama, Y., Keen, S., \& West, P. (2016) Speculative Design and Heterogeneity in Indigenous Nation Building, DIS 2016.

Ayala, M. R. O., Jiménez, A. R. H., Marisol, I. R. G. Y., \& Hoyo, A. R. (2015). Socialization of Knowledge through Collaborative Projects. The Renovarte Café Case. American Journal of Educational Research, 3(3), pp. 259-262.

Bidwell, N.J., Standley, P., George, T., \& Steffensen, V. (2008). The Landscape's Apprentice: Lessons for Place-Centred Design from Grounding Documentary. In Proceedings of DIS 2008, 88-98. https://doi.org/10.1145/1394445.1394455

Carroll, J., Rosson. M. (2007). Participatory design in community informatics. Design Studies 28. doi:10.1016/j.destud.2007.02.007

Christie, M. (2005). Aboriginal Knowledge Traditions in Digital Environments, Australian Journal of Indigenous Education, 34, p. 61-66.

Du, J.T. (2017). Research on Indigenous People and the Role of Information and Communications Technology in Development: A Review of the Literature, Journal of the Australian Library and Information Association, 66(4), 344-363, doi: 10.1080/24750158 2017.1397857.

Dyson, L., Underwood, J. (2006) Indigenous people on the web. Journal of Theoretical and Applied Electronic Commerce Research, April, 1(1), pp. 65-76.

Eades, D. (2013). Aboriginal ways of using English. Aboriginal Studies Press 
First Nations Media (n.d.) https://firstnationsmedia.org.au/projects/broadband-bush. Retrieved, August 15, 2021

Fishbein, M., Ajzen, I. (1975). Belief, attitude, intention, and behavior: An introduction to theory and research. Reading, MA, USA: Addison-Wesley Publishing Company.

George, R., Nesbitt, K., Donovan, M., \& Maynard, J. (2011). Focusing on Cultural Design Features for an Indigenous Website. Proceeding of the Australasian Conference on Information Systems 2011, article 17. https://aisel.aisnet.org/acis2011/17

Goldfinch, T., Jolley, L., Prpic, J. K., Leigh, E. (2016). Australian Engineering Educators' Perceptions of Indigenous Cultures and Challenges of Minority Inclusion. 44th SEFI Conference, 12-15 September 2016, Tampere, Finland

ICTV (n.d.) https://ictv.com.au/about-us. Retrieved August 15, 2021.

Indigital (n.d.) https://www.indigital.net.au/. Retrieved August 15, 2021.

Iversen, O. S., Halskov, K., \& Leong, T. W. (2012). Values-led participatory design. CoDesign, 8(2-3), 87-103.

Kietzmann, J., Hermkens, K., McCarthy, I., \& Silvestre, B. (2011). Social Media? Get Serious! Understanding the Functional Building Blocks of Social Media. Business Horizons, 54 (3), 241-251. doi:10.1016/j.bushor.2011.01.005

Keeping Culture (n.d.) https://www.keepingculture.com/. Retrieved August 15, 2021.

Kutay, C., Aurum, A., (2007). Knowledge transformation for education in software engineering. International Journal of Mobile Learning and Organisation, 1, pp. 58-80.

Kutay, C. (2010). Issues for Australian Indigenous Culture Online. In E. Blanchard, D. \& Allard (Eds.), Handbook of Research on Culturally-Aware Information Technology: Perspectives and Model, pp. 337-361. Hershey, PA, USA: IGI Global.

Kutay, C., (2011). HCI study for culturally useful knowledge sharing. Lecture Notes in Computer Science (including subseries Lecture Notes in Artificial Intelligence, Volume 7697 LNCS, Heidelberg, Germany: Springer Verlag, pp. 69-78.

Kutay, C., Mooney, J., Riley, L. \& Howard-Wagner, D. (2012). Experiencing Indigenous knowledge online as a community narrative. The Australian Journal of Indigenous Education, 41(1), pp. 47-59.

Kutay, C. (2014.) One Person's Culture is Another One's Entertainment. Proceedings of Interactive Entertainment, Newcastle, December, 2014 doi: https:/dl.acm.org/ doi/proceedings/10.1145/2677758

Kutay, C. (2018). Advances in Culturally-Aware Intelligent Systems and in Cross-Cultural Psychological Studies. In C. Faucher (ed.). Springer Science and Business Media Deutschland GmbH, pp. 63-96. Intelligent Systems Reference Library, vol. 134.

Kutay, C. (2019). Locating Knowledge. Archives and Manuscripts, 47(1), pp. 72-93.

Kutay (2021) Aboriginal Knowledge Online. ab-Original: Journal of Indigenous Studies and First Nations, forthcoming. 
Lightning Runners (2018). http://heartbeat.westernsydney.edu.au/play-lightning-runners/. Retrieved August 15, 2021.

Limba (n.d.) https://limba.com.au/. Retrieved August 15, 2021.

Lukosch, S., Klebl, M., Buttler, T., \& Hackel, M. (2009). Eliciting Requirements with Audiobased Collaborative Storytelling. In Proceedings of the International Conference on Group Decision and Negotiation (GDN), pp. 99-104.

Mignerat, M., Rivard, S. (2009). Positioning the institutional perspective in information systems research, Journal of Information Technology, 24(4), pp. 369-391. https://doi.org/ 10.1057/jit.2009.13

Mukurtu (n.d.) https://mukurtu.org/. Retrieved August 15, 2021.

Nakata, M. (2010). The Cultural Interface of Islander and Scientific Knowledge. The Australian Journal of Indigenous Education, 39(Supplement), pp. 53-57.

Nonaka, I., Takeuchi, H. (1995). The knowledge-creating company. How Japanese companies create the dynamics of innovation, Oxford University Press, Oxford.

Ormond-Parker, L., Sloggett, R. (2008). Local archives and community collecting in the digital age. Archival Science: International Journal on recorded Information, 12(2), pp. 191-212.

Pascoe, B. (2014). The Dark Emu, Magabala Books, Broome, WA, Australia.

Povinelli, E. (1993). Labour's Lot: The power, history and culture of Aboriginal action, University of Chicago Press, Il, USA.

Pradhan, S., Beetson, S., \& Kutay, C. (2018). Building Digital Entrepreneurial Platform through Local Community Activity and Digital Skills in Aboriginal Australia, presented at Australasian Conference on Information Systems, Sydney, http://www.acis2018.org/wpcontent/uploads/2018/11/ACIS2018_paper_187.pdf

Prayaga, P., Rennie, E., Pechenkina, E., \& Hunter, A. (2017). Digital Literacy and Other Factors Influencing the Success of Online Courses in Remote Indigenous Communities. 10.1007/978-981-10-4062-7_12. Retrieved August 15, 2021.

Radoll, P. (2009). UNDER DEVELOPMENT: Reconstructing Australian Aboriginal governance by systems design. Interactions, 16(3), pp. 46-49.

Radoll, P. (2010). Stone Chips to Silicon Chips. PhD Thesis, Australia National University, Canberra.

Radoll, P. (2015). Aboriginal peoples, Education and Information and Communication Technologies in Australia. In N. Bidwell \& H. Winschiers-Theophilus (Eds.), At the Intersection of Indigenous and Traditional Knowledge and Technology Design. CA, USA: Informing Science Press.

Rigney, L.I. (2001). A First Perspective of Indigenous Australian Participation in Science: Framing Indigenous Research Towards Indigenous Australian Intellectual Sovereignty, Kaurna Higher Education Journal, 7, pp. 1-13.

Rice, E., Haynes, E., Royce, P., \&Thompson, S. (2016). Social media and digital technology use among Indigenous young people in Australia: a literature review. International Journal for Equity in Health, 15, 81. 
Sawhney, H., Ratnadeep, V. (2008). Lateral Connectivity at the Margins: Ritual Communication and Liminality on Aboriginal Networks. Science, Technology and Society, 13(2), 345-368. https://journals.sagepub.com/doi/abs/10.1177/0971721808013002 09

Senadheera, V., Warren, M. \& Leitch, S. (2017). Social media as an information system: improving the technological agility, Enterprise Information Systems, 11(4), pp. 512-533. doi: 10.1080/17517575.2016. 1245872

Sidorova, A., Evangelopoulos, N., Valacich, J. S., \& Ramakrishnan, T. (2008). Uncovering the intellectual core of the information systems discipline, MIS Quarterly, 32(3), pp. 467-482.

Silva, S.C., Feitosa, W., Duarte, P., \& Vasconcelos, M. (2020). How to increase engagement on social media using the honeycomb model: A case study in a Portuguese HR company, REGE - Revista de Gestão, 27(2), pp. 153-167. https://doi.org/10.1108/REGE-02-2019-0030

Smith, C., Burke, H., \& Ward, G. (2000). Globalisation and Indigenous People: Threat or Empowerment? In C. Smith \& G. Ward (Eds.), Indigenous Cultures in an Interconnected World, Vancouver, BC, Canada: University of British Columbia Press, pp. xviii-24

Soro, A., Brereton, M., Taylor J.E., Lee Hong, A.G., \& Roe, P. (2016). Cross-cultural dialogical probes. In K. Awori \& N. Bidwell (Eds.), Proceedings of the First African Conference on Human Computer Interaction. Association for Computing Machinery, United States of America, pp. 114-125.

Suchman, L. (2002). Located accountabilities in technology production. Scandinavian Journal of Information Systems, 14, pp. 91-105

Sveiby, K.-E., Skuthorpe, T. (2006)., Treading Lightly, Allen \& Unwin, Sydney, Australia.

Tacchi, J., Watkins, J. (2007). Participatory Research and Creative Engagement with ICTs. In ACM Sensys workshop on Sensing on Everyday Mobile Phones in Support of Participatory Research, November 6, 2007.

Verran, H., Christie, M. (2007). Using/Designing digital technologies of representation in Aboriginal Australian knowledge practice, Human Technology, 3(2), pp. 214-27.

Verran, H, Christie, M, Anbins-King, B, Van Weeren T., \& Yunupingu, W. (2007). Designing digital knowledge management tools with Aboriginal Australians, Digital Creativity, 18(3), pp. 129-142, doi: 10.1080/14626260701531944

Wasko, M. M., Faraj, S., \& Teigland, R. (2004). Collective action and knowledge contribution in electronic networks of practice. Journal of the Association for Information Systems, $5(11)$, p. 2.

Wilson, S. (2008). Research Is Ceremony, Indigenous Research Methods. Black Point, Nova Scotia, Canada: Fernwood Publishing.

Winschiers-Theophilus, H., Bidwell, N., \& Blake, E. (2012). Community Consensus: Design Beyond Participation. Design Issues, 28(3), 89-100. doi: 10.1162/DESI_a_00164

Zaman, T., Winschiers-Theophilus, H. (2015). Penan's Oroo' Short Message Signs (PO-SMS): Co-design of a Digital Jungle Sign Language Application. In J. Abascal, S. Barbosa, M. Fetter, T. Gross T., P. Palanque, \& M. Winckler (Eds.), Human-Computer Interaction - 
INTERACT 2015. INTERACT 2015. Lecture Notes in Computer Science, 9297. Cham, Switzerland: Springer Publishing Company. https://doi.org/10.1007/978-3-319-226682_38

Copyright: (c) 2021 authors. This is an open-access article distributed under the terms of the Creative Commons Attribution-NonCommercial 3.0 Australia License, which permits noncommercial use, distribution, and reproduction in any medium, provided the original author and AJIS are credited.

doi: https://doi.org/10.3127/ajis.v25i0.2907

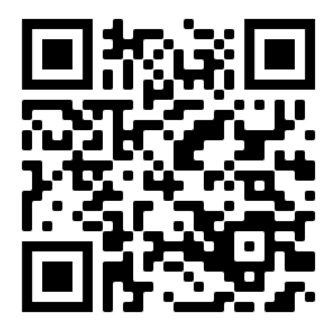

